\title{
EDUCACIÓN A DISTANCIA PARA EL SALTO ACADEMICO - PARTE I
}

\section{Enrique Ferroni, Hernando Velásquez y Luz Mary Chavarro.}

\section{INTRODUCCIÓN}

Desde el punto de vista de la regulación, Colombia tiene definidas las modalidades educativas. Contempla la presencialidad y la distancia (Ley 30, Art. 15) e interpreta la tecnología como herramienta de apoyo a la mediación en cualquiera de las modalidades (Decreto 2566, Art. 10).

Por otra parte y como una premisa, la constante observada en innumerables investigaciones públicas y privadas de la educación superior en Colombia, es la baja cobertura. En relación con las poblaciones potenciales (entre 17 y 24 años), la oferta educativa nacional cubre $16 \%$ y el promedio de crecimiento anual no supera el $4 \%{ }^{1}$. Es así como la modalidad de educación a distancia se ha ido dibujando de manera clara y eficaz como una respuesta a esta problemática.

\section{RESUMEN}

Con el advenimiento de las nuevas tecnologías de la información y la comunicación -NTI-, la educación a distancia se está configurando como una alternativa preponderante en todos los países del mundo, máxime para naciones con bajísimos niveles de cobertura, movilidad y acceso a la educación con calidad, como el caso colombiano.

Para abordar esta temática como un proyecto viable, el Politécnico Grancolombiano inició un análisis de la oferta educativa en los ámbitos nacional e internacional, el cual, sumado al ejercicio de determinar las necesidades locales colombianas por sectores productivos, hace parte de la base para definir los programas más adecuados, las poblaciones demandantes y las regiones más necesitadas, en esta modalidad.

\section{PALABRAS CLAVE}

Acceso, aprendizaje autónomo, asincronía, autonomía, cadenas productivas, calidad, clusters, cobertura, competencias, currículo, distancia, empleo, formación dual, innovación, inte- gral, internet, investigación, mediación, mesas sectoriales, modalidad, modelo, movilidad, paradigma, poblaciones, polos de desarrollo, potencial, presencialidad, redes de desarrollo, remoto, sincronía, telemática, tendencia, valores, virtualidad.

\section{ABSTRACT}

With the advent of new information and communications technologies -NITC, distance learning is becoming a prevailing alternative in all countries in the world; more so for countries with very low levels of coverage, mobility and access to quality education, as is the case in Colombia.

To approach this issue as a viable project, the Politécnico Grancolombiano began an analysis of educational supply in the national and international arenas, which, on top of the exercise in determining local Colombian needs by productive sectors, is part of the basis in determining the most appropriate programs, population demand, and the regions with the greatest need in this modality. 
El Politécnico Grancolombiano, a sus 25 años de actividades académicas presencialesy dentro desu macropolítica "El Salto Académico", contempla la educación a distancia (EAD) como una alternativa para el fomento de la educación superior, justificada por la tendencia global y reconocidas virtudes como cobertura, asincronía, apertura, etcétera.
El Politécnico Grancolombiano, a sus 25 años de actividades académicas presenciales y dentro de su macropolítica "El Salto Académico", contempla la educación a distancia (EAD) como una alternativa para el fomento de la educación superior, justificada por la tendencia global y reconocidas virtudes como cobertura, asincronía, apertura, etcétera.

En consecuencia, acomete el desarrollo de un análisis alrededor de la oferta de programas en el orden mundial, acorde con las tendencias y necesidades para la modalidad, observando la representatividad y pertinencia para su productividad y competitividady la del país. Involucra la demanda potencial a través de un estudio de mercado y propone, como resultado, un modelo curricular por competencias integrales con los programas que mayor conveniencia presentan por temáticas, regiones y demanda.

Dado que acometer esta modalidad implica tener claridad en diferentes cuestionamientos, el equipo de EAD responde qué es la educación a distancia, por qué y para qué abordarla, y deja para una segunda publicación los con qué, para quién, cómo y dónde.

\section{RESEÑA DE AUTOR}

La dirección del equipo de educación a distancia está a cargo de Enrique Ferroni Guzmán, administrador de empresas egresado del Politécnico y quien se ha desempeñado en la Vicerrectoría de Programas Especiales de la Institución a lo largo de diez años, ocho de ellos, en el Departamento de Formación Empresarial.

Hernando Velásquez Montoya, Coordinador académico especializado en docencia universitaria tiene 20 años de experiencia en educación a distancia.

Luz Mary Chavarro Porras, Asesora pedagógica especializada en mercadeo y publicidad, cuenta con 15 años de experiencia en diseño curricular por competencias y virtualización de contenidos.

\section{ANÁLISIS DELA EDUCACIÓN A DISTANCIA}

ANTECEDENTES

A pesar de ser muchos los investigadores que se han preocupado por establecer el camino recorrido por la educación a distancia en el contexto mundial, no existen investigaciones que permitan precisar con certeza el origen de la educación a distancia. Sin embargo, varios autores opinan que esta modalidad irrumpe en el mundo educativo a finales del siglo XVIII y logra incursionar de manera decisiva en el siglo XIX, dejando a su paso infinidad de seguidores y opositores.

Hay quienes consideran sus orígenes en el nacimiento de la escritura como es el caso de los egipcios, y a partir de allí la relacionan con el proceso histórico de la humanidad, con todas aquellas actividades en las que las personas intercambiaban y presentaban posiciones y opiniones a través de cartas, en las que juegan un papel fundamental filósofos como Séneca, Platón y San Agustín, entre otros.

No podemos desconocer que, de alguna forma, dichos hechos o acontecimientos remotos marcan de manera informal y asistemática los orígenes de la educación a distancia, pero para efectos prácticos nos ubicaremos en el siglo XVIII, de acuerdo con los datos presentados por B. Holmberg, quien demuestra que en 1728 La Gaceta de Boston publica un anuncio sobre un material autoinstructivo para ser enviado a los estudiantes y que ofrece la tutoría por correspondencia ${ }^{2}$.

María Elvira Vásquez E³ , en una breve reseña sobre la educación a distancia, la ubica

2 HOLMBERG, Borge. Educación a Distancia. Situación y perspectivas. Buenos Aires: Editorial Kapelusz, 1985.

3 Pontificia Universidad Javeriana. Educación a distancia un reto a la imaginación. Programa Universidad Abierta 20 años. Bogotá: Panamericana Formas e Impresos Ltda., 1994. 
a finales del siglo XIX como una alternativa para superar los problemas del conocimiento generados por la Revolución Industrial, en el nacimiento de las primeras escuelas por correspondencia en Suecia que buscaban cualificar personal en áreas ocupacionales.

Algunos sucesos que se deben resaltar son: el trabajo desarrollado por Isaac Pitman en Estados Unidos en 1840, con el diseño y la ejecución de un programa de taquigrafía por correspondencia. El periódico publicado por el distrito minero de Pensylvania, el Minming Herald, que buscaba capacitar en métodos de prevención de accidentes y técnicas de minería. Las escuelas radiofónicas en Francia en la época de la posguerra. La formación en lenguas modernas para la enseñanza del francés a jóvenes y a adultos en Berlín. Experiencias que se multiplicaron y se fueron expandiendo a lo largo de Australia, Europa Occidental y América, y es así como la enseñanza por correspondencia, da origen a la educación a distancia.

Peters $^{4}$ establece el año 1929 como la fecha de partida para las primeras experiencias de enseñanza universitaria a distancia, y la ubica en la entonces Unión Soviética. Registra 18 nombres de universidades que impartían en aquella época aprendizaje a distancia. Otras experiencias pioneras las tenemos en la República Sudafricana 1947, en China 1960 y en la Open University del Reino Unido 1969. Sin embargo, se afirma que la expresión formal de educación a distancia se empieza a usar con frecuencia en la década de los setenta.

En la actualidad, instituciones públicas y privadas ofrecen a la población europea diversas posibilidades de educación a distancia. Dentro de las experiencias más amplias sobre esta modalidad educativa en Europa, encontramos el Centre National d'Enseignement à Distance (CNED) en Francia, que en 1995 tenía matriculados en programas de educación a distancia a 350.000 estudiantes de Francia y de 170 países más. La Open University, considerada como la universidad más grande del Reino Unido, tiene más de 200.000 alumnos matriculados actualmente en sus cursos y está adoptando la internet como medio para proporcionar materiales educativos más interactivos y actualizados a sus alumnos. Desde su apertura, más de dos millones de personas han adelantado cursos de enseñanza superior y en la actualidad, de las matrículas anuales, $60 \%$ se realizan on line.

España tiene actualmente dos universidades prominentes en educación a distancia: la Universidad Nacional de Educación a Distancia (UNED) creada en 1970 en Madrid y la Universidad Oberta de Catalunya (UOC) fundada en 1995 en Barcelona. En virtud de la Ley de Reforma Universitaria de 1983, la UNED goza de la misma estructura académica y administrativa y la misma autonomía financiera y jurídica que el resto de las universidades. Se encuentra en todo el territorio nacional y cuenta con 61 centros asociados y 14 centros en el exterior. Tiene en la actualidad 152.885 alumnos a distancia y 29.562 en educación permanente (on line), de los cuales 2.171 estudian en el extranjero. La Universidad Oberta de Catalunya (UOC) es un claro ejemplo de una estructura 
moderna de educación a distancia universitaria que usa medios telemáticos.

Existe, hoy en día, una gran variedad de instituciones y planteamientos en los diferentes países de la Unión Europea con respecto a la educación a distancia. La característica fundamental de todas estas universidades radica en un gran prestigio, experiencia y alto número de matrículas, así como el fomento de la investigación e innovación en los métodos de educación a distancia.

\section{PRINCIPIOSYFUNDAMENTOS}

Desde otra perspectiva, Casas Armengol ${ }^{5}$, en una revisión conceptual de la educación a distancia, destaca dos definiciones: la de Moore, para quien este tipo de educación consiste en "aquellos métodos de enseñanza en los cuales, debido a la separación física entre alumnos y profesores, las fases interactivas y preactivas de la enseñanza, son conducidas a través de medios impresos, mecánicos o electrónicos”. Por su parte, Wedemeyer señala que "el alumno está a distancia del profesor, gran parte o todo el tiempo, durante el proceso de enseñanzaaprendizaje".

Así, el aspecto esencial reside en que no hay interacción presencial directa entre docente y alumno. Esta comunicación no presencial se realiza, entonces, a través de los medios de comunicación, ofrece una manera de aprendizaje diferencial al estudiante, brinda una opción de estudio al adulto y contribuye a reducir la problemá- tica que afronta la educación tradicional sobre todo en los países en vías de desarrollo, como son la baja cobertura, las dificultades de acceso y el costo, entre otros.

Casas Armengol ${ }^{6}$, dentro de los principales rasgos de la educación a distancia, cita los siguientes:

-Población estudiantil relativamente dispersa y en su mayoría adulta.

- Orientación auto instruccional.

- Cursos producidos con uso predominante de textos impresos, pero combinándolos con otros medios.

- Comunicaciones masivas.

- Comunicación organizada en dos direcciones.

-Estructuras curriculares flexibles en módulos y créditos.

A las características anteriores se debe agregar la incorporación de las Nuevas Tecnologías de la Comunicación y la Información (NTIC), como una de las propiedades más recientes de la instrumentación de la educación a distancia ${ }^{7}$. Se resalta así la presencia de la práctica de la comunicación en este contexto, en el que no se puede adoptar una tecnología de comunicación sin realizar la correspondiente adaptación e integración del proceso educativo.

Al respecto, Barandarian ${ }^{8}$ señala tres reorientaciones importantes:

I. Se incorporan nuevos elementos dentro del proceso de enseñanza-aprendizaje al

5 CASAS, Armengol, M. Universidad sin clases. Educación a distancia en América Latina. Venezuela: OEAUNA-KAPELUSZ, 1986.

6 Ibídem.

7 RUBINYI, R., Sicpioni, C. y Lee, P. New Technologies for Distance Education: A Needs Assesment at the Delivery Site. Educational Technology, 1991.

8 BARANDIARAN DE GARLAND, E. Panorama de la Teleducación en América Latina. Televisión y Educación. México: ILCE, 1994. 
incluirse el uso de medios como vehículo de contenido, lo cual modifica el mismo concepto de aula.

II. Se determinan nuevos roles para los integrantes del proceso de comunicación educativa.

III. Como consecuencia de I y II, se usa una nueva metodología según los nuevos elementos y roles.

Como se puede observar, podríamos presentar diferentes conceptos, características y particularidades de la educación a distancia, según el autor o investigador al cual se haga referencia. Sin embargo, en todos encontramos puntos comunes que permiten definir los principios, objetivos y características de la modalidad a distancia. Para objeto de este análisis se toman los definidos por Velásquez ${ }^{9}$.

La educación a distancia apropia una serie de principios que propenden por el desarrollo integral del estudiante, un modelo metodológico con esquemas administrativos dinámicos y flexibles, un concepto de aprendizaje y evaluación con una nueva visión del currículo caracterizado por lo abierto, permanente, la contextualización socio-cultural del conocimiento, la integración teórico-práctica y la autoformación de los estudiantes.

Estas perspectivas educativas constituyen los ejes orientadores para los principios rectores de la educación a distancia, entre los cuales enunciamos los siguientes:

- Se entiende el aprendizaje como un proceso autónomo donde el estudiante hace apropiación de los conocimientos teóricos y la aplicación de los mismos, a partir de la toma de conciencia sobre su responsabilidad en cuándo, cómo y cuánto debe aprender, para saber más y mejor sobre un área o un quehacer específico. Se expresa en el comportamiento que asume la persona que aprende al convertirse en autorealizador y autocontrolador del proceso formativo.

- Se parte del sujeto objeto de formación, eje del proceso de aprendizaje, motor del mismo, desde la identificación de las necesidades de formación hasta la generación de espacios de interacción con su entorno, que le permiten no solamente su mejoramiento y cualificación personales y de su grupo social, sino del entorno en el cual está inserto.

- Exige una actitud reflexiva permanente frente al acto de aprender, que favorece la comprensión de los contenidos y permite la aplicación del conocimiento en constante interacción con el medio natural y sociocultural.

- La educación a distancia brinda posibilidades para adquirir y generar conocimientos, desarrollar habilidades y destrezas a lo largo de la vida de la persona; tiene en cuenta su estado actual educativo y cultural, y la ubica en el desarrollo histórico del conocimiento teniendo en cuenta sus valores sociales y culturales para que, una vez los apropie, genere actitudes creativas frente a ellos, y propenda, de esta manera, por el concepto de educación permanente.

- Exige una ruptura de los aprendizajes individualistas para avanzar hacia compromisos colectivos y formas participativas y democráticas, a través de activida-
La educación a distancia apropia una serie de principios que propenden por el desarrollo integral del estudiante, un modelo metodológico con esquemas administrativos dinámicos $y$ flexibles, un concepto de aprendizajey evaluación con una nueva visión del currículo caracterizado por lo abierto, permanente, la contextualización socio-cultural del conocimiento, la integración teórico-práctica y la autoformación de los estudiantes. 
des basadas en la cooperación, la interacción, el diálogo y la solidaridad.

- La educación a distancia se afianza en las necesidades, condiciones, aspiraciones, expectativas, intereses y posibilidades particulares de las personas que aprenden, al ofrecer currículos abiertos y flexibles, métodos, criterios y formas de administración, acordes con las características sociales y culturales de las personas.

- Se busca que durante el proceso de aprendizaje se articule el saber humanístico con el conocimiento científico y técnico, para impedir la ruptura entre el hombre que piensa y el hombre que actúa o trabaja y el hombre que se relaciona con una sociedad. De esta forma el ser humano se vislumbra y desarrolla de manera integral.

- En todo momento propende por la integración de la teoría y la práctica, que redunde en un conocimiento apropiado y pertinente para la transformación y el cambio del medio en el cual se aprende.

- La evaluación hace parte del proceso global de aprendizaje; su dimensión es participativa y autoformativa. Se efectúa permanentemente y es el estudiante su primer autoevaluador.

Fruto de los principios mencionados, el modelo metodológico de la educación a distancia propende por el logro de los siguientes objetivos:

I. Democratizar el acceso a la educación en cuanto permite crear condiciones de diferente orden que faciliten el acceso a ésta al romper las limitaciones de tiempo y espacio, hacer compatible el estudio con el trabajo, convertir el modelo educativo tradicional en un proceso de estudio independiente alimentado mediante diversos métodos y medios, trabajar bajo un modelo tutorial acorde con las necesidades e intereses de los estudiantes.

II. Propiciar un aprendizaje autónomo y ligado a la experiencia teniendo en cuenta la autonomía objeto central del modelo educativo, debido a que el docente tutor no está en relación presencial permanente con el estudiante, por lo que corresponde al estudiante autodirigir el proceso educativo para llegar a ser capaz de pensar y actuar por sí mismo con sentido crítico, teniendo en cuenta diferentes puntos de vista tanto en el ámbito moral como en el intelectual, sin desconocer el contexto en el cual está inserto.

III. Impartir una enseñanza innovadora y de calidad. Trabajar no sólo alrededor de la conservación, transmisión y difusión del conocimiento, sino también alrededor de su problematización y de la concienciación del estudiante, para que de esta manera sea capaz de producir nuevos saberes, transformar la realidad y desarrollar nuevos valores. Sólo en la medida en que la educación proporciona conocimientos, habilidades y destrezas al hombre, que se traducen en comportamientos y desempeños que le permitan cambiar y transformar su realidad, la educación podrá considerarse como innovadora y de calidad.

IV. Fomentar la educación permanente. Se trata de establecer un vínculo, una continuidad entre los eslabones de la cadena educativa, para concebir de esta forma, la educación extensiva a toda la vida humana. Así, el punto esencial pasa a ser la interac- 
ción entre la educación y la vida concreta de los individuos entre los diferentes grupos y medios sociales. El punto de partida de la educación permanente es el proceso de desarrollo y maduración de los individuos, sometidos a diversos estímulos e influencias a través de un conjunto de medios que facilitan la interacción de los actos educativos.

V. Lograr la excelencia en la educación a distancia. Para responder adecuadamente a las demandas del desarrollo dinámico y complejo de la sociedad colombiana en general, se necesitan instituciones educativas ágiles y flexibles que planeen y desarrollen modelos y ambientes de aprendizaje innovadores, tanto dentro como fuera de las instituciones, actualizando así su oferta de manera constante para mantenerse al día frente a los avances tecnológicos y los requerimientos cambiantes de la comunidad.

Con base en lo anterior, la educación a distancia busca trabajar la formación de un profesional crítico, creativo, innovador, participativo, solidario, forjador de una cultura de cambio, para lo cual la institución universitaria requiere el diseño de espacios y escenarios que permitan la sensibilización y capacitación de los docentes tutores en modelos innovadores de los procesos formativos; promover la creación de foros, discusiones para el intercambio de experiencias e información; desarrollar programas que incentiven, en los docentes tutores y en los estudiantes, el compromiso por la investigación pura y aplicada.

Las nuevas tecnologías de la comunicación y de la información han hecho asequible los medios virtuales a innumerables personas que antes los percibían como imposibles. Se ha creado un nuevo medio de relación, un espacio de comunicación atemporal. Los medios virtuales nos ofrecen la posibilidad de crear entornos nuevos de relación y como tales, deben ser tratados de manera distinta para extraer de ellos el máximo potencial. La riqueza de estos nuevos entornos, todavía en fase de exploración, es enorme y su poder reside en la capacidad de saber explotar el máximo de sus posibilidades.

El uso y manejo de las NTIC exige del educador, un cambio de hábitos, desarrollo de la creatividad, conocimiento del medio, además de los aspectos educativos y comunicativos como la participación del receptor en un contexto de enseñanza-aprendizaje, entre otros. En otras palabras, debe tener un dominio tanto en el tratamiento comunicativo como en el didáctico-pedagógico del contenido o mensaje.

La educación no puede ser ajena al potencial que los nuevos espacios de relación virtual aportan. Ante la rapidez de la evolución tecnológica, la educación debe manifestarse claramente y situar la tecnología en el lugar que le corresponde; un medio eficaz para garantizar la comunicación, la interacción, la información y, por supuesto, el aprendizaje.

La relación que se establece entre educación y medios virtuales es una relación de creatividad. La oportunidad de volver a pensar de forma creativa la educación, así como los mecanismos y dinámicas que le son propias a partir de la tecnología como excusa, es un factor claramente positivo. La educación convencional y la educación a distancia están convergiendo en un mismo paradigma, en un mismo espacio de reflexión y de análisis que estimula los pro-
Ante la rapidez de la evolución tecnológica, la educación debe manifestarse claramente y situar la tecnología en el lugar quele corresponde; un medio eficazpara garantizar la comunicación, la interacción, la información $y$, por supuesto, el aprendizaje. 
cesos de optimización de la acción educativa, especialmente en el ámbito de la educación superior universitaria y permanente.

Educación y medios virtuales se complementan en la medida en que la educación puede gozar de las posibilidades de creatividad de la virtualidad para mejorar o diversificar sus procesos y acciones encaminados a la enseñanza y al aprendizaje, mientras que la virtualidad como sistema se beneficia de la metodología de trabajo educativo y de comunicación, necesaria en aquellos casos habituales en los que la finalidad de la relación en la red sobrepasa la búsqueda de información.

Las estadísticas que se presentan a continuación y que han sido tomadas de ExitoExportador.com, con datos actualizados al 3 de febrero del 2005, permiten visualizar la importancia de esta:

\begin{tabular}{|l|r|r|r|r|r|r||}
\hline \multicolumn{7}{|c||}{ ESTADÍSTICAS MUNDIALES DEL INTERNET Y DE POBLACIÓN } \\
\hline \multicolumn{1}{|c|}{ Regiones } & $\begin{array}{c}\text { Población } \\
(2005 \text { EST.) }\end{array}$ & $\begin{array}{c}\% \text { Población } \\
\text { mundial }\end{array}$ & $\begin{array}{l}\text { Usuarios, dato } \\
\text { más reciente }\end{array}$ & $\begin{array}{c}\text { Crecimiento } \\
(2000-2005)\end{array}$ & $\begin{array}{c}\% \text { Población } \\
\text { (Penetración) }\end{array}$ & $\begin{array}{c}\text { (\%) de } \\
\text { usuarios }\end{array}$ \\
\hline África & $900,465,411$ & $14.0 \%$ & $12,937,100$ & $186.6 \%$ & $1.4 \%$ & $1.6 \%$ \\
\hline Asia & $3,612,363,165$ & $56.3 \%$ & $266,742,420$ & $133.4 \%$ & $7.4 \%$ & $32.6 \%$ \\
\hline Europa & $730,991,138$ & $11.4 \%$ & $230,923,361$ & $124.0 \%$ & $31.6 \%$ & $28.3 \%$ \\
\hline Oriente Medio & $259,499,772$ & $4.0 \%$ & $17,325,900$ & $227.8 \%$ & $6.7 \%$ & $2.1 \%$ \\
\hline Norte América & $328,387,059$ & $5.1 \%$ & $218,400,380$ & $102.0 \%$ & $66.5 \%$ & $26.7 \%$ \\
\hline Latinoamérica / & $546,917,192$ & $8.5 \%$ & $55,279,770$ & $205.9 \%$ & $10.1 \%$ & $6.8 \%$ \\
\hline Caribe & $33,443,448$ & $0.5 \%$ & $15,838,216$ & $107.9 \%$ & $47.4 \%$ & $1.9 \%$ \\
\hline Oceanía & $6,412,067,185$ & $100.0 \%$ & $817,447,147$ & $126.4 \%$ & $12.7 \%$ & $100.0 \%$ \\
\hline TOTAL MUNDIAL & & & & & & \\
\hline
\end{tabular}

\begin{tabular}{|l|r|r|r|r|r|r|}
\hline AMÉRICA DEL SUR & $\begin{array}{c}\text { Población } \\
\text { actual (2004) }\end{array}$ & $\begin{array}{c}\text { Usuarios, } \\
\text { año 2000 }\end{array}$ & $\begin{array}{l}\text { Usuarios, dato } \\
\text { más reciente }\end{array}$ & $\begin{array}{c}\text { Crecimiento } \\
(2000-2004)\end{array}$ & $\begin{array}{c}\text { \% Población } \\
\text { (Penetración) }\end{array}$ & $\begin{array}{c}\% \text { de } \\
\text { usuarios }\end{array}$ \\
\hline Argentina & $37,740,400$ & $2,500,000$ & $4,100,000$ & $64.0 \%$ & $10.9 \%$ & $11.6 \%$ \\
\hline Bolivia & $8,879,600$ & 120,000 & 270,000 & $125.0 \%$ & $3.0 \%$ & $0.8 \%$ \\
\hline Brasil & $183,199,600$ & $5,000,000$ & $20,551,168$ & $311.0 \%$ & $11.2 \%$ & $58.0 \%$ \\
\hline Chile & $15,482,300$ & $1,757,400$ & $3,575,000$ & $103.4 \%$ & $23.1 \%$ & $10.1 \%$ \\
\hline Colombia & $45,299,400$ & 878,000 & $2,000,000$ & $127.8 \%$ & $4.4 \%$ & $5.6 \%$ \\
\hline Ecuador & $12,664,700$ & 180,000 & 537,900 & $198.8 \%$ & $4.2 \%$ & $1.5 \%$ \\
\hline Guayana Franc. & 196,800 & 2,000 & 2,000 & $0.0 \%$ & $1.0 \%$ & $0.0 \%$ \\
\hline Guyana & 869,100 & 3,000 & 125,000 & $4066,7 \%$ & $14.4 \%$ & $0.4 \%$ \\
\hline Paraguay & $5,469,600$ & 20,000 & 100,000 & $400.0 \%$ & $1.8 \%$ & $0.3 \%$ \\
\hline Perú & $27,553,000$ & $2,500,000$ & $2,500,000$ & $0.0 \%$ & $9.1 \%$ & $7.1 \%$ \\
\hline Suriname & 460,300 & 11,700 & 20,000 & $70.9 \%$ & $4.3 \%$ & $0.1 \%$ \\
\hline Uruguay & $3,428,900$ & 370,000 & 400,000 & $8.1 \%$ & $11.7 \%$ & $1.1 \%$ \\
\hline Venezuela & $24,120,500$ & 950,000 & $1,274,400$ & $34.1 \%$ & $5.3 \%$ & $3.6 \%$ \\
\hline TOTAL Sur América & $365,366,600$ & $14,292,100$ & $35,455,468$ & $148.1 \%$ & $9.7 \%$ & $100.0 \%$ \\
\hline & & & & & & \\
\hline
\end{tabular}

NOTAS: (1) Las estadísticas de usuarios del internet fueron actualizadas en febrero 3 del 2005. (2) Las cifras de población se basan en los datos actuales de gazetteer.de. (3) Las cifras de usuarios más recientes corresponden a Nielsen//NetRatings, ITU, NIC's, ISP's y otras fuentes confiables. (4) Las cifras de crecimiento fueron determinadas comparando el dato de usuarios actuales del Internet con los datos del año 2000 de las estadísticas de ITU. (5) La reproducción de estas tablas y estadísticas se autoriza, con la condición de citar a www.ExitoExportador.com como la fuente original. 


\section{AMÉRICA LATINA Y COLOMBIA}

El siglo XX es testigo del desarrollo e importancia que adquiere la educación a distancia, al penetrar el mundo de la educación superior y estructurarse de manera formal y sistemática con diversas experiencias, tal como se mencionó precedentemente, debido a los fundamentos filosóficos, pedagógicos, epistemológicos y sociales por los que propende, las características particulares que presenta, la manera como rompe los paradigmas educativos tradicionales y cómo contribuye a resolver las problemáticas que el siglo XX trajo consigo.

Las características particulares de América Latina, en la década del sesenta, encuentran en la educación a distancia un puntal de desarrollo, por permitirle resolver problemas de analfabetismo, solventar la insuficiencia que presenta la educación formal y no formal, llegar a regiones apartadas y de escaso desarrollo y contribuir de esta forma a la calidad de vida de las personas. Aquí vale la pena destacar experiencias como la del Instituto Tecnológico de Estudios Superiores de Monterrey en México; la UNED de Costa Rica; la UNA de Venezuela; el Centro de Tele Educación de la Universidad Católica en el Perú; en Argentina, la Universidad de Buenos Aires; en Brasil, la Universidad de Luján; en Chile, la Universidad Católica de Santiago y la Universidad de Chile.

De esta manera, al igual que en Europa, Estados Unidos y Canadá, las décadas del sesenta y setenta se caracterizaron por el auge que tuvo la educación a distancia en América Latina. Así, el número de instituciones y de estudiantes en esta modalidad creció inconmensurablemente en todos los países; en algunos llegó a romper fronteras y contar con estudiantes de países vecinos.

En lo que hace referencia a Colombia, la Universidad del Valle, la Universidad Santo Tomas, la Universidad Javeriana y la Universidad de Antioquia son pioneras en esta modalidad. UNISUR hoy la UNAD, abre sus puertas a los colombianos en 1981 mediante la Ley 52 de este mismo año, como una institución pública de educación superior que propende exclusivamente por el fomento y desarrollo de esta modalidad, con cobertura nacional.

En el año $2000^{10}$, cuarenta y cinco instituciones de educación superior colombianas ofrecían programas de pregrado y posgrado, número que creció semestralmente dadas las condiciones y características cambiantes de la educación superior en Colombia, además del contexto mundial el cual exigió y continúa exigiendo cambios radicales al mundo educativo en cuanto a garantizar la equidad social, ampliar la cobertura, buscar la excelencia y calidad, acercar el mundo educativo al sistema productivo, vincular la educación nacional con el entorno internacional, apropiar tecnología, fortalecer la investigación y desarrollar acciones cooperativas, entre otras.

De esta manera podemos afirmar que la educación a distancia en Colombia tiene una trayectoria de cincuenta años, como un proceso de facilitación de oportunidades para personas que, al no disponer de tiempo, no podían iniciar su educación para el trabajo siguiendo los estándares educativos determinados por la educación presencial diurna o nocturna. Así, la 
educación por correspondencia, una de las primeras formas de educación a distancia tal como se indicó anteriormente, hizo su aparición en Colombia y permitió la formación en la industria y el campo, factores que ayudaron a desarrollar mejores procesos productivos en beneficio social, no solo para el empresario sino para el individuo mismo.

Aunque esta modalidad ha sido una estrategia de formación reconocida, el sistema educativo colombiano aún no ha explotado todos sus beneficios y aunque se ha tratado de seguir un ejercicio riguroso para determinar su impacto, no sólo en el desarrollo de los procesos educativos, sino en los beneficios formativos alcanzados por los que han aprendido en ella, la comunidad académica colombiana tiene apreciaciones muy diversas que van desde la apatía absoluta hasta el interés por querer explorar su tecnología.

En la actualidad, en el país existen 83 instituciones de educación superior con 441 programas activos y 168 inactivos, en esta modalidad. La siguiente tabla permite conocer en detalle los datos establecidos.

\section{Programas a distancia en Colombia, junio 2004}

Instituciones de educación superior

\begin{tabular}{|l|r|r|r|r|}
\hline \multirow{2}{*}{ IES } & \multirow{2}{*}{ No IES } & \multicolumn{3}{l|}{ Estado de los Programas } \\
\cline { 5 - 5 } & 37 & 246 & 143 \\
\hline Universidades & 26 & 146 & 14 \\
\hline Instituciones universitarias & 13 & 29 & 5 \\
\hline Instituciones tecnológicas & 5 & 15 & 6 \\
\hline Técnicas profesionales & 1 & 3 & 0 \\
\hline Régimen especial & 1 & 2 & 0 \\
\hline Escuela tecnológica & 83 & 441 & 168 \\
\hline Total & & &
\end{tabular}

Fuente: Viceministerio de Educación Superior - Colombia: SNIES 2004

La dinámica que impulsa el paradigma del conocimiento no es ajena a Colombia, lo que ha conducido a que las instituciones que trabajan en el campo del conocimiento comiencen a buscar múltiples formas para que la información, materia prima del conocimiento, pueda ser asequible e incorporada al proceso educativo, sufra la correspondiente transformación y se constituya en elemento de intercambio y de ganancia para sus usuarios. De esta manera, las NTIC han sido apropiadas por instituciones educativas naciona- les en la perspectiva de que la virtualidad se convierta en un elemento de cotidianidad de los procesos educativos.

En tal sentido, la virtualidad no es un algo nuevo en la historia de la humanidad. Para Ángel Facundo ${ }^{11}$, la educación virtual es una experiencia reciente, que ha tenido una expansión vertiginosa en el mundo entero.

Como ha sucedido en otros campos, la aplicación de las tecnologías digitales a la educación se ha desarrollado desde dos vertientes estratégicas. Una primera consiste

11 FACUNDO, Ángel Hernando. La Educación Superior Virtual en Colombia. UNESCO, Instituto Internacional para la Educación Superior en América Latina y el Caribe, 2003. http://www.iesalc.unesco.org.ve/estudios/ regionales_lat/EducVirtual.pdf 
en aplicar las nuevas tecnologías a cursos y programas de formación y capacitación para estudiantes en sitios remotos, "a distancia”. La segunda aplica las NTIC a la investigación y desarrollo de virtualidad en aspectos como la administración y servicios académicos y, por supuesto, la docencia (presencial y remota) privilegiando la tecnología informática. Entre estos dos polos de desarrollo se da un amplio espectro de realizaciones.

Desde esta perspectiva, el Politécnico Grancolombiano busca, con el programa de educación a distancia, encontrar un camino que le dé vigencia a la modalidad y le permita su reconocimiento, teniendo en cuenta que dispone de un paradigma propio que la orienta, la impulsa en su desarrollo donde, desde un principio, se vislumbran varios escenarios de aprendizaje, entre ellos el virtual, que con apoyo de las nuevas pedagogías y tecnologías de la información permiten el tránsito de la educación bajo esta modalidad.

\section{NUESTRA SITUACIÓN ACTUAL} POLITÉCNICO GRAMCOLOMBIANO

Actualmente, la Fundación ofrece dos programas técnicos profesionales, uno para el sector financiero y el otro para el sector transporte de pasajeros y carga.

Siete programas tecnológicos del sector servicios, tres dirigidos al sector bancario, asegurador y financiero, como son administración bancaria, administración financiera y administración de seguros; uno hacia el sector agropecuario con administración de empresas agropecuarias. Todos estos programas le permiten al estudiante acceder al programa profesional en administración de empresas.
Los tres programas restantes corresponden a: Mercadeo y Publicidad, donde el estudiante nuevamente puede optar por el ciclo profesional en mercadeo y publicidad; administración de sistemas, que en su ciclo profesional conduce a Ingeniería de Sistemas y, por último, Administración Ambiental como una respuesta al equilibrio del ecosistema.

En el ciclo profesional encontramos nueve programas, de los cuales tres permiten el desarrollo de la cadena de formación desde el ciclo tecnológico, tal y como ya se mencionó. Los seis restantes corresponden en su orden a: Comunicación Social-Periodismo, Contaduría Pública, Ingeniería Industrial, Matemáticas, Medios Audiovisuales, Negocios Internacionales, en algunos de los cuales se puede ver la orientación de la Institución hacia sectores productivos en los que se requieren nuevos profesionales, hecho que conserva la marcada vocación por las áreas económicas, administrativas y contables.

En relación con los programas de posgrado, el Politécnico Grancolombiano ofrece siete especializaciones en las que nuevamente se halla una gran tendencia hacia las áreas económicas, administrativas y contables, tal y como se puede observar con los siguientes programas: Gerencia de Mercadeo, Gerencia de Finanzas, Mercadeo Político, Mercadeo Ecológico, Gerencia de Riesgos y Seguros, Gerencia de Proyectos de Telecomunicaciones y especialización en Comunicación Corporativa.

Hay que tener en cuenta que el PEI contempla los programas de Derecho, Psicología y Artes de la Escena.

UNIVERSIDAD DEL ISTMO DE PANAMÁ- UDI

Se trabaja con la oferta de programas de la UDI en la perspectiva de vislumbrar 
vocación y tendencias de la universidad, así como de abrir la posibilidad a futuras alianzas estratégicas en la oferta académica e intercambios educativos en la modalidad a distancia, que genera una colaboración dinámica para ambas organizaciones, con los consabidos beneficios.

Los resultados son los siguientes: La Universidad ofrece un programa técnico bilingüe en Call Center, seis tecnológicos en las áreas de negocios marítimos, contabilidad por sistemas, finanzas y banca, mercadeo y publicidad, turismo y hotelería y recursos humanos; nueve licenciaturas, cinco de las cuales permiten la movilización del estudiante del ciclo tecnológico al profesional; licenciatura en contabilidad por sistemas, licenciatura en mercadeo y publicidad, licenciatura en finanzas $y$ banca, licenciatura en producción audiovisual y licenciatura en recursos humanos.

Otras licenciaturas son: derecho y ciencias políticas, negocios internacionales, administración de sistemas y administración logística.

En otras áreas cuenta con tres ingenierías: industrial, informática con énfasis en redes, e informática en dirección a sistemas de información.

En cuanto a los programas de posgrado cuenta con cuatro especializaciones: docencia superior, gestión portuaria y transporte internacional, gestión de calidad y alta gerencia. Además se ofrecen siete MBA, en: comercio y mercadeo internacional, formulación y evaluación de proyectos, banca y finanzas internacionales, educación con énfasis en docencia de la educación superior, gestión de calidad, gerencia de empresas agropecuarias y recursos humanos.

Adicionalmente se puede observar que UDI, al igual que el Politécnico Grancolombiano, presenta una vocación por las áreas económicas, administrativas y contables.

\section{LA OFERTA DE NUEVOS PROGRAMAS DE ORDEN NACIONAL}

Determinar las tendencias en pregrado y posgrado, es fundamental, pues esta información fortalece la toma de decisiones al ampliar el abanico de posibilidades por considerar, programas que no solamente marquen la pauta en las necesidades formativas nacionales, sino que generen la opción de romper fronteras en un futuro próximo, cuando la entidad cuente con registro calificado de los programas a distancia.

Aclaramos que los programas que aparecen relacionados en el cuadro adjunto, no obedecen a tendencias de carreras tradicionales como el derecho, la odontología, la administración o las ingenierías tradicionales, sino a programas relativamente nuevos en respuesta a las tendencias tecnológicas, que finalmente marcan una pauta en los elementos de escogencia de carrera actuales:

\begin{tabular}{|l|l|}
\hline \multicolumn{2}{|l|}{ Ingenierías } \\
\hline Mecatrónica & Digital de arte y diseño tridimensional \\
\hline Logística & En telecomunicaciones \\
\hline En teleinformática & Eléctrica \\
\hline Electrónica & Bioingeniería \\
\hline En diseño de productos & De procesos \\
\hline En producción & De control \\
\hline
\end{tabular}


Estos programas siguen el desarrollo tecnológico de subsectores industriales como la industria gráfica y afines, la industrial metalmecánica, eléctrica y electrónica, autopartes y automotores, los desarrollos en las tecnologías de la información y la comunicación.

También se encuentra una serie de ingenierías que atienden el sector agropecuario:

\begin{tabular}{|l|l|l|}
\hline \multicolumn{3}{|c|}{ Ingenierías } \\
\hline Acuícola & Sanitaria & Geológica \\
\hline
\end{tabular}

Estas permiten atender, nuevamente, tendencias tecnológicas sectoriales y cadenas productivas como minerales e hidrocarburos, piscicultura y exportación, camarón de pesca y de cultivo y, cadena de atún. Otros programas que atiende el sector agropecuario son: plantaciones agrícolas tropicales, apicultura, gestión ambiental y veterinaria, los cuales responden a necesidades reales del sector.

Se destaca en el estudio la presencia de programas en mercadeo y negocios internacionales que son, sin lugar a dudas, una necesidad del sector comercial y de los demás sectores económicos (industrial, servicios y agropecuario). Sin embargo, pareciera ser, por las denominaciones de estos programas, que se hace más énfasis sobre la ciencia administrativa que sobre la disciplina del mercadeo y la acción comercial, en cuanto presentan nombres compuestos como: administración de mercadeo, publicidad y ventas, administración en mercadeo y publicidad, administración de mercadeo, mercadeo y ventas, mercadeo y publicidad, ingeniería de ventas e ingeniería comercial, cuando los estudios muestran una necesidad del mercadeo y la comercialización por la globalización e internacionalización, además de una no respuesta del profesional actual por el área financiera.

Con base en los programas de finanzas, banca, economía y contaduría, se puede afirmar que siguen siendo relevantes en el desarrollo económico del país. No obstante, hay que reflexionar sobre si responden a los acelerados cambios en las estructuras institucionales del sector financiero y bancario, pues existe una marcada tendencia negativa en la oferta educativa hacia ellos que no contribuye a su desarrollo y jalonamiento, sino que los deja relegados al ámbito local al no incorporar tecnologías de punta ${ }^{12}$.

Programas como el teatro, la música, las artes plásticas, que tradicionalmente han sido ofrecidos por entidades de educación no formal, se constituyen en una nueva posibilidad de formación profesional en instituciones de educación superior.

El advenimiento de la Ley 30 de 1992, generó proliferación, en el país, con programas de crecimiento exagerado en la oferta, como es el caso de ciencias de la salud, que presenta un crecimiento de $1.248 \%$ para el año 1999, en la oferta tradicional (medicina, enfermería, odontología), y que deja de lado necesidades de formación en los campos de la gerontología, la geriatría y el desarrollo de la infancia. De otro lado, administración ocupa el segundo lugar en este crecimiento, con $648 \%$ de incremento (administración acompañada de diferentes disciplinas del saber, tal como se anotó 
anteriormente). Le siguen las ingenierías tradicionales, con $235 \%$ y las ciencias jurídicas con $220 \%{ }^{13}$.

\section{OFERTA DE NUEVOS PROGRAMAS DE ORDEN INTERNACIONAL}

Elámbito internacional presenta la siguiente situación en programas que responden a tendencias tecnológicas, más que a programas tradicionales; el recorrido se centra en países como Alemania, Francia, España, Estados Unidos, México y Argentina:

\begin{tabular}{|c|c|}
\hline \multicolumn{2}{|c|}{ Sector Comercial } \\
\hline $\begin{array}{c}\text { Marketing } \\
\text { internacional }\end{array}$ & $\begin{array}{l}\text { Ingeniería de } \\
\text { ejecución de } \\
\text { marketing }\end{array}$ \\
\hline $\begin{array}{l}\text { Negocios } \\
\text { internacionales }\end{array}$ & $\begin{array}{l}\text { Ingeniería de } \\
\text { ejecución de } \\
\text { finanzas }\end{array}$ \\
\hline Banca y finanzas & $\begin{array}{c}\text { Finanzas } \\
\text { internacionales }\end{array}$ \\
\hline $\begin{array}{l}\text { Comunicación } \\
\text { comercial }\end{array}$ & $\begin{array}{l}\text { Publicidad } \\
\text { y relaciones } \\
\text { públicas }\end{array}$ \\
\hline Piloto comercial & \\
\hline
\end{tabular}

Todos muestran una tendencia acentuada hacia la globalización e internacionalización de la economía, incluso con una oferta amplia y enfocada a otros países a través de convenios.

Ver cuadros sector servicios y sector industrial

En el sector agropecuario es marcada la tendencia de atención a los recursos hídricos y a la ingeniería ambiental.

Cabe anotar que existe una gran tendencia hacia programas de pregrado alrededor del desarrollo de los recursos humanos, como es el caso de la ingeniería de ejecución de recursos humanos, como también hacia la gestión y la gerencia de empresas. Otros programas que sobresalen son los relacionados con los estudios políticos.

Las artes plásticas, la dramaturgia, las artes escénicas, son programas que presentan una amplia oferta en todos los niveles de educación superior.

\begin{tabular}{|c|c|}
\hline & Sector servicios \\
\hline Subsector salud & Tecnología en emergencia médica \\
\hline Programas no & Gerontología \\
\hline tradicionales & Desarrollo de la infancia \\
\hline & Ciencias de la computación \\
\hline & Comunicación multimedial \\
\hline & Extracción de conocimientos a partir de datos (doctorado) \\
\hline Nuevas & Ingeniería de ejecución en informática de gestión \\
\hline tecnologías & Fotografía creativa \\
\hline & Fotografía e imágenes digitales \\
\hline comunicación y & Diseño audiovisual \\
\hline la información & Imagen y sonido \\
\hline & Cine y televisión \\
\hline & Multimedia y arte gráfico \\
\hline & Telecomunicaciones \\
\hline & Organización de eventos con énfasis en los eventos \\
\hline & Comunicación comercial global \\
\hline turismo & Hotelería y turismo internacional \\
\hline & Administración de empresas turísticas \\
\hline
\end{tabular}

13 ICFES, Población estudiantil por división politico- administrativa, Orden, instituciones y programas. Bogotá, 2002. En: www.icfes.gov.co 


\begin{tabular}{|c|c|}
\hline & tor industrial \\
\hline \multirow{14}{*}{ Ingenierías } & Mecatrónica \\
\hline & Digital y de diseño tridimensional \\
\hline & Ciencias e ingeniería de los materiales \\
\hline & Mecánica \\
\hline & Digital \\
\hline & Electrónica \\
\hline & De diseños o productos \\
\hline & Aeronáutica \\
\hline & Aviación comercial \\
\hline & Eléctrica \\
\hline & De transporte \\
\hline & Redes y telecomunicaciones \\
\hline & Comunicación de datos de control de calidad \\
\hline & Logística \\
\hline \multirow{3}{*}{ Subsector textil y confecciones } & Textiles y vestuario \\
\hline & Diseño de modas \\
\hline & Diseño de interiores \\
\hline
\end{tabular}

PROGRAMASA DISTANCIA EN EL ÁMBITO NACIONAL

En quinto lugar se relacionan los programas a distancia nacionales. Esta informa- yáreas de atención.

\section{Programas a Distancia - Nacional}

Nacional: propensión por programas de tecnologías blandas y licenciaturas
Atención prehospitalaria

Regencia de farmacia

Estudios políticos y resolución de conflictos

Ecología y manejo ambiental

Licenciatura en educación popular

Educación básica

Educación preescolar

Literatura y lenguas

Biología

Filosofía

Psicología

Acuicultura

Pecuaria

Ecología y manejo ambiental

Producción agropecuaria

Sector agropecuario; uno de los más atendidos a través de esta modalidad
Administración de empresas agropecuarias

Recursos naturales renovables

Administración ambiental de recursos naturales

Producción animal

Zootecnia

Manejo agroforestal

Manejo agroecológico y poscosecha

Nutrición animal sostenible 


\begin{tabular}{|l|l|}
\hline \multirow{4}{*}{ Programas a Distancia - Nacional } \\
\hline \multirow{4}{*}{ Otros programas } & Gestión ejecutiva \\
\cline { 2 - 2 } & Gestión empresarial \\
\cline { 2 - 2 } & Tecnología jurídica \\
\cline { 2 - 2 } & Bellas artes \\
\cline { 2 - 2 } & Administración de economía solidaria \\
\cline { 2 - 2 } & Administración de empresas \\
\cline { 2 - 2 } & Contaduría \\
\hline & Relaciones internacionales y estudios políticos \\
\hline & Maltrato infantil \\
\cline { 2 - 2 } & Gerontología \\
\hline
\end{tabular}

\begin{tabular}{|l|l|}
\hline \multicolumn{1}{|c|}{ Programas a Distancia - Nacional } \\
\hline \multirow{4}{*}{$\begin{array}{l}\text { Tecnologías } \\
\text { duras }\end{array}$} & Ingeniería de alimentos \\
\cline { 2 - 2 } & Ingeniería civil \\
\cline { 2 - 2 } & Programas de construcción en ingeniería y arquitectura \\
\cline { 2 - 2 } & Gestión del transporte \\
\cline { 2 - 2 } & Sistemas \\
\cline { 2 - 2 } & Electrónica \\
\cline { 2 - 2 } & Gestión industrial \\
\cline { 2 - 2 } & Gestión en obras civiles y construcción \\
\hline
\end{tabular}

Hay que reconocer que la oferta de programas a distancia, en el país, atiende necesidades reales de formación en el sector agropecuario y tiende a ser más flexible frente a los desarrollos tecnológicos, además de presentar una amplia oferta de tecnólogos y profesionales, lo cual permite el desarrollo de una cadena de formación.

\section{PROGRAMASA DISTANCIA EN EL ÁMBITO INTERNACIONAL}

Las dos instituciones europeas que han estado históricamente a la vanguardia en la oferta educativa bajo la modalidad a distan- cia: UNED de España y la Open University del Reino Unido, presentan los siguientes programas:

\begin{tabular}{|l|l|}
\hline \multicolumn{2}{|c|}{$\begin{array}{c}\text { Programas a Distancia - } \\
\text { Internacional }\end{array}$} \\
\hline \multirow{4}{*}{$\begin{array}{l}\text { Licenciaturas } \\
\text { en: }\end{array}$} & Ciencias físicas \\
\cline { 2 - 2 } & Ciencias químicas \\
\cline { 2 - 2 } & Matemáticas \\
\cline { 2 - 2 } & $\begin{array}{l}\text { Geografía e } \\
\text { historia }\end{array}$ \\
\cline { 2 - 2 } & Psicopedagogía \\
\cline { 2 - 2 } & Educación \\
\cline { 2 - 2 } & Lingüística \\
\hline
\end{tabular}




\begin{tabular}{|l|l|}
\hline \multicolumn{4}{|c|}{ Programas a Distancia - Internacional } \\
\hline \multirow{5}{*}{ Ciencias } & Psicología \\
\cline { 2 - 2 } & Sociología \\
\cline { 2 - 2 } & Política \\
\cline { 2 - 2 } & Filología \\
\cline { 2 - 2 } & Derecho \\
\cline { 2 - 2 } & Ciencias económicas \\
\cline { 2 - 2 } & Economía \\
\cline { 2 - 2 } & Administración \\
\hline \multirow{5}{*}{ Otras áreas de atención } & Turismo \\
\cline { 2 - 2 } & Negocios internacionales \\
\cline { 2 - 2 } & Administración de cuidados en salud \\
\hline & Enfermería \\
\cline { 2 - 2 } & Aviación \\
\cline { 2 - 2 } & Sistemas \\
\cline { 2 - 2 } & Criminalística \\
\hline & Industrial \\
\cline { 2 - 2 } & Informática de gestión \\
\cline { 2 - 2 } & Informática de sistemas \\
\cline { 2 - 2 } & De seguridad \\
\hline
\end{tabular}

En contraste con los programas que se ofrecen en el ámbito nacional, la oferta de programas a distancia en el exterior se centra en el campo profesional y en ellos priman las tecnologías blandas y las ciencias.

\section{MESAS SECTORIALES, POLOS DE DESARROLLO, REDES DE DESARROLLO, CLUSTERS, CADENAS PRODUCTIVAS}

El estudio de estos elementos fundamentales en la economía del país, se aborda teniendo como referente las diversas investigaciones y recomendaciones de expertos, tanto en el sector educativo como de trabajo, en las que se refleja una marcada preocupación por la articulación entre estos.

Se destacan factores como la falta de un análisis explícito del fenómeno económico-productivo que conduzca al diseño de un modelo pedagógico curricular, para formar profesionales con una base científica y humanística que favorezca, a la vez, la movilidad y adaptabilidad profesional y que le permita al sujeto aprender a tomar decisiones en un ambiente de cambio e incertidumbre.

Los objetivos de este estudio son favorecer la ubicación en el contexto macro económico, micro económico y productivo del país, e identificar oportunidades, tendencias y necesidades del mercado de trabajo, las cuales deben ser atendidas por el sector educativo a través de la oferta de programas.

Veamos el concepto e importancia de los términos: mesas sectoriales, polos de desarrollo, redes de desarrollo, clusters y cadenas productivas.

- Mesas sectoriales: las mesas sectoriales son escenarios de concertación del Sistema Nacional de Formación para el Trabajo, donde participan activamente empresarios, gremios, sector público, organizaciones de trabajadores, centros de investigación y entidades educativas.
En contraste con los programas que se ofrecen en el ámbito nacional, la oferta de programas a distancia en el exterior secentra en el campo profesionaly en ellos priman las tecnologías blandas y las ciencias. 
Su objetivo es la elaboración y validación de las normas de competencia laboral y la apropiación del proceso de evaluación y certificación del desempeño de los trabajadores colombianos, con base en las normas elaboradas. Algunas de sus funciones son:

- Determinar las áreas y subáreas de desempeño y los niveles ocupacionales que requieren normalización.

- Desarrollar normas de competencia laboral.

- Promover la participación del sector productivo en el proceso de elaboración de normas de competencia laboraly titulaciones.

- Designar los equipos técnicos, controlar y aprobar la calidad de sus produc- tos: caracterización, mapas funcionales y titulaciones.

- Establecer los perfiles de los expertos que integran los equipos técnicos.

- Designar uno o más equipos técnicos, según el área o subárea de desempeño laboral, sobre los que se van a elaborar normas de competencia laboral.

Estas mesas fueron creadas como política de gobierno a partir de 1997, con el fin de adecuarse para la competitividad y liderar la construcción de un sistema que articule la oferta educativa técnica, pública y privada, para regularla y potenciarla. En la actualidad Colombia cuenta con treinta y siete (37) mesas sectoriales, dentro de las cuales se destacan:

\begin{tabular}{|l|l|}
\hline Agroindustria del banano & Agua potable y saneamiento básico \\
\hline Artesanías & Avícola \\
\hline Azúcar & Cadena pecuaria \\
\hline Café & Construcción \\
\hline Cuero, calzado y marroquinería & Educativo \\
\hline Eléctrico & Frutas y hortalizas \\
\hline Gas & Industria gráfica y afines \\
\hline Lácteos y cárnicos & Logística \\
\hline Cadena forestal, madera & Mantenimiento \\
\hline Mercadeo & Equipo técnico especializado \\
\hline Metalmecánica & Minería \\
\hline Palma de aceite & Plásticos \\
\hline Recursos humanos & Salud \\
\hline Servicios financieros & Soldadura \\
\hline Telecomunicaciones & Teleinformática \\
\hline Textiles y confecciones & Transporte \\
\hline Turismo & Pymes comerciales \\
\hline
\end{tabular}

Algunos de los estudios sectoriales realizados por estas mesas y tenidos en cuenta como objeto de este estudio son: sector educativo, industria gráfica y afines, logística, mercadeo, recursos humanos, servicios financieros, telecomunicaciones, tele- informática, textiles y confecciones, sector transporte y sector turismo.

- Polos de desarrollo tecnológico: zonas geográficas o regiones que por sus características de ubicación y producción, 
permiten la consolidación de proyectos científicos y tecnológicos alrededor de un área determinada. Los proyectos que se generen en torno a un polo de desarrollo contribuirán a la creación de empleo, a consolidar la infraestructura comercial del mismo, a incrementar su productividad y mejorar la calidad.

Los polos de desarrollo tecnológico en Colombia son:

- Turismo

- Pesca industrial

- Minerales, hidrocarburos y productos derivados

- Redes de desarrollo ${ }^{14}$ para responder a uno de los objetivos del Plan Estratégico Exportador y hacer competitiva la actividad exportadora, se formuló la Política Nacional de Productividad y Competitividad con el propósito de mejorar la productividad de las empresas y aumentar la competitividad de los productos colombianos, con miras a fomentar exportaciones en cantidad y valor agregado.

Como parte de la agenda decenal contemplada en la Política Nacional de Productividad y Competitividad, se creó la Red Colombia Compite, como un esquema de trabajo que permite articular esfuerzos y recursos entre sector público, privado y la academia, para abordar tareas complejas que requieren un trabajo transversal en torno a la solución de obstáculos a la competitividad en cada uno de los factores que contempla el
Foro Económico Mundial (FEM) como determinantes para el entorno productivo de los países.

La Red Colombia Compite - RCC es liderada por la Presidencia de la República como instrumento de la Política Nacional de Competitividad. La coordinación general es realizada por el Ministerio de Comercio, Industria y Turismo, con el acompañamiento de un representante del sector privado. Dentro de las redes especializadas objeto de trabajo de esta política de gobierno están:

\begin{tabular}{|l|l|}
\hline Capital Humano & Ciencia y tecnología \\
\hline Energía y Gas & Finanzas \\
\hline Gerencia & Internacionalización \\
\hline $\begin{array}{l}\text { Institucionalidad } \\
\text { yobernabilidad }\end{array}$ & Telecomunicación \\
\hline $\begin{array}{l}\text { Tecnologías de la } \\
\text { información y la } \\
\text { comunicación }\end{array}$ & Trabajo \\
\hline Transporte & \\
\hline
\end{tabular}

- Cluster ${ }^{15}$ : los clusters son grupos de cadenas productivas con retroalimentación positiva, donde las ventajas competitivas de unas se refuerzan con las otras y adoptan la definición de la "Política Nacional para la Productividad y Competitividad".

Otra forma de entenderlos, según Michael Porter, gurú de la estrategia empresarial, es la concertación geográfica de compañías e instituciones vinculadas entre sí, (masas críticas en un sitio) que alcanzan éxitos competitivos. Los 
límites del cluster están definidos por los lazos de las firmas y de las instituciones que sean pertinentes para competir. Los elementos centrales de un cluster son:

- Orientar la demanda hacia el consumidor final de la cadena.

- Generar vínculos estrechos entre las empresas.

- Promover la regionalización, dada su localización concertada.

- Aumentar la productividad por la retroalimentación positiva entre cadenas diferentes.

- Competir y cooperar a la vez.

- Alcanzar éxitos por ventajas competitivas que se refuerzan.

Los cluster de mayor relevancia en Colombia son:

- Autopartes, automotores.

- Cuero y marroquinería.

- Equipo y maquinaría eléctrica y electrónica.

- Electrónica profesional.

- Forestal, pulpa, papel e industrias gráficas.

- Hortalizas y frutas.

- Ropa interior femenina.

-Vivienda.

- Cadenas productivas: las cadenas productivas se definen como la integración de los diversos eslabones de la estructura económica, para construir ventajas competitivas sostenibles que permitan dar una mayor inserción a los mercados internacionales.

El Plan Estratégico Exportador 19992009 contiene objetivos que buscan aumentar y diversificar la oferta expor- table de bienes y servicios, en función de la demanda mundial.

Lo que buscan los convenios es una concertación entre el sector público y privado, en los cuales se definan estrategias de mediano y largo plazo para integrar los diferentes eslabones de las cadenas productivas.

El sector empresarial ha combinado una serie de acciones claramente definidas en el Plan Estratégico Exportador, las cuales buscan fortalecer el sector productivo del país con miras a aumentar la oferta exportable. A continuación se relacionan las cadenas productivas que actualmente presentan un nivel de importancia significativa en el desarrollo del país.

\begin{tabular}{|l|l|}
\hline $\begin{array}{l}\text { Autopartes, } \\
\text { automotores }\end{array}$ & $\begin{array}{l}\text { Cosméticos, aseo } \\
\text { y jabón }\end{array}$ \\
\hline $\begin{array}{l}\text { Artefactos } \\
\text { domésticos }\end{array}$ & $\begin{array}{l}\text { Equipo y } \\
\text { maquinaria } \\
\text { eléctrica y } \\
\text { electrónica }\end{array}$ \\
\hline $\begin{array}{l}\text { Electrónica } \\
\text { profesional }\end{array}$ & Metalmecánica \\
\hline Camarón de cultivo & Cadena de atún \\
\hline Cadena de papa & $\begin{array}{l}\text { Piscicultura y } \\
\text { exportación }\end{array}$ \\
\hline Lácteos & Cárnicos \\
\hline Algodón & Arroz \\
\hline Azúcar & Banano \\
\hline Cacao & Café \\
\hline Caucho & Cereales \\
\hline $\begin{array}{l}\text { Avicultura y } \\
\text { porcicultura }\end{array}$ & Cítricos \\
\hline Ganado bovino & $\begin{array}{l}\text { Frutales de } \\
\text { exportación }\end{array}$ \\
\hline Forestal madera & Guadua \\
\hline Panela & Oleaginosas \\
\hline Plátano & Tabaco \\
\hline
\end{tabular}


PROGRAMAS SELECCIONADOS SEGÚN TENDENCIASY NECESIDADES, POR SECTOR ECONÓMICO

TENDENCIASY MEEESIDADES

Los resultados de la búsqueda y el análisis de información permitieron al equipo de educación a distancia del Politécnico Grancolombiano, visualizar un abanico de temáticas susceptibles de ser ofrecidas en la educación superior, en cualquiera de los tres sectores y en el campo de las artes, las ciencias y la administración. Contrastados con datos relacionados con el empleo y de acuerdo con la vocación institucional, tendencias, necesidades tecnológicas y sectores económicos: finanzas, banca y seguros, mercadeo, negocios internacionales, transporte, teleinformática, telecomunicaciones, logística, contaduría, producción audiovisual, ambiental (el Centro de Educación a Distancia dispone de información sobre otras posibilidades de formación; tiene en cuenta solamente tendencias tecnológicas, polos de desarrollo y necesidades del sector productivo, de acuerdo con los sectores comercial y de servicios, publicidad e investigación de mercados e industrial y agropecuario).

\section{Sector económico}

\section{Sector comercial y de servicios}

El sector terciario o comercial y de servicios, es uno de los sectores clave en la economía actual. Consiste en la prestación de servicios a las personas y a las empresas de tal manera que puedan dedicar su tiempo a la producción.

Aunque se tiende a pensar que la actividad terciaria es una función urbana que se desarrolla más en las grandes ciudades y las hace crecer, hoy la encontramos incluso en pequeñas ciudades y pueblos. Dado que la actividad terciaria va del comercio a la administración, pasando por toda clase inimaginable de servicios a la sociedad, su nivel de importancia en la oferta de empleo y en la especialización de las empresas del sector primario y secundario, es cada día mayor.

Actualmente, en los países desarrollados, el sector terciario es el que más contribuye al producto interno bruto (PIB). Sin embargo, eso es producto del desarrollo del sector primario y de la industria. El aumento del sector terciario es propio de los países desarrollados, pero no necesariamente es un indicador de desarrollo, ya que en los países subdesarrollados hay un amplio sector de servicios personales y poco cualificados como el servicio doméstico. Un amplio sector comercial tampoco garantiza el desarrollo de un país, sobre todo si no se dedica a cubrir las necesidades que demanda la sociedad, de acuerdo con la región o si no mejora los mercados globales que atiende.

Ante la economía terciarizada y globalizada de Colombia, al sector comercio y de servicios se le plantean grandes expectativas y posibilidades de desarrollo, máxime si se tiene en cuenta que éste representa aproximadamente el 50\% del PIB; específicamente el comercio es una de las actividades que más aporta a la actividad económica nacional. En términos de empleo, el sector servicios representaba aproximadamente un $47 \%$ en 1989 , que aportaba tan solo el 36\% en 1968. El comercio pasó de aportar un $11.1 \%$ del empleo en 1970 a un 25,4\% en 1995.

El comercio interno de Colombia es heterogéneo puesto que en él se da un proceso de cambio con estructuras tradi-
El sector terciario o comercialy de servicios, es uno de los sectores clave en la economía actual. Consiste en la prestación de servicios a las personasya las empresas de tal manera que puedan dedicar su tiempo a la producción. 
Colombia cuentacon variados medios de publicidad como son siete canales de televisión, 670 emisoras de radio registradas, 40 periódicos de orden nacional y regionaly centenares de revistas orientadas a sectores específicos de la población. cionales y con la incorporación, al mismo tiempo, de una tecnología comercial nueva y de formas comerciales adaptadas a la evolución del mercado.

Tendencias de largo alcance como el incremento de los niveles de ingreso disponible, la recomposición de los gastos familiares, la mayor urbanización, la incorporación de la mujer al mercado laboral, la disminución del tamaño de la familia, la penetración de los medios de comunicación masivos, entre otros, han logrado un cambio profundo en los hábitos de compra del consumidor colombiano.

A continuación reseñamos algunos apartes de la caracterización del mercadeo que ratifican la importancia de este sector económico.

En 1998 el sector de los servicios logró las mejores utilidades en mucho tiempo; las comunicaciones pasan por un período de altas inversiones y en algunas empresas se presentan grandes utilidades como en otras, grandes pérdidas. En este subsector, la consulta cuenta con empresas que dieron grandes utilidades como $E l$ Tiempo, Revista Semana y El Colombiano, y con empresas que sufren una profunda reestructuración como El Espectador. Empresas en transición que están conquistando mercados como Celumovil y empresas muy exitosas como Mejía y Asociados, en la televisión.

\section{Publicidad e investigación de mercados}

La industria de la publicidad expresada en sus tres componentes, los publicistas, las agencias y los medios, cumple a caba- lidad con el objeto de proporcionar a la población colombiana acceso ilimitado a información a través de medios independientes y diversos.

Desde la perspectiva económica, la publicidad fortalece el proceso de toma de decisiones por parte del consumidor al proporcionarle información que le permita escoger en un ambiente competitivo de ventas.

Colombia cuenta con variados medios de publicidad como son siete canales de televisión, 670 emisoras de radio registradas, 40 periódicos de orden nacional y regional y centenares de revistas orientadas a sectores específicos de la población.

Esta abundancia de medios, por su independencia y su profesionalismo, hacen posible el desarrollo de las empresas, de las marcas y en general, de la economía nacional.

La inversión publicitaria en el año 1992 era de solo 531.000 millones, cifra que con la apertura económica en pleno apogeo llegó a 1,287 billones de pesos en 1994 y en 1998 a 4,161 billones.

Estas cifras gigantescas son pequeñas frente a la realidad. Estudios adelantados por Napoleón Franco señalan que por cada peso invertido en publicidad, se invierten dos en promoción, relaciones públicas y otras formas de invertir en mercadeo.

El sector publicitario genera más de 21.000 empleos $^{16} \mathrm{y}$ tiene plenamente identificados más de 25.000 productos en las agencias de publicidad registradas legalmente en el país"17. 
Los párrafos anteriores dan cuenta de la razón por la cual se propone un programa en comunicación comercial o publicidad y programas antes mencionados como mercadeo o marketing internacional y negocios internacionales, teleinformática y telecomunicaciones.

También se contempla trabajar en gerontología, desarrollo de la infancia, y hotelería y turismo.

\section{SECTOR INDUSTRIAL}

Tal y como se plantea en infinidad de documentos e investigaciones, la industria fue el sector motor de la economía desde el siglo XIX hasta la Segunda Guerra Mundial. Era el sector económico que más aportaba al PIB en el concierto mundial y el que más mano de obra ocupaba. Desde entonces y con el desarrollo de las tecnologías, aumentó la productividad. De igual manera y con el desarrollo de los servicios, el sector industrial ha pasado a un segundo término aunque continúa siendo esencial puesto que no puede haber servicios sin desarrollo industrial.

En la actualidad, diversos factores favorecen su desarrollo. Entre ellos podemos destacar un compromiso político que permita favorecer la industria a partir de mano de obra barata o una ley laboral favorable a los empresarios, que garantice suelo industrial barato, exima de impuestos a las empresas, subvencione u ofrezca servicios a las compañías. Todas estas medidas y algunas otras de tipo legal, fiscal o bancario, estimulan el sector.

Otro agente determinante para el sector industrial son los factores ambientales de atracción o rechazo de una planta. Dependiendo de la cantidad de residuos que genere en su proceso de elaboración del producto, la planta podrá ser más o menos contaminante para el medio en el que se ubica. De acuerdo con la localización global, el clima es un factor limitante de la actividad industrial, máxime cuando del clima depende la capacidad regeneradora de la naturaleza. Además, los climas extremos dificultan el funcionamiento de la propia planta y la aglomeración en las cercanías de la fuerza de trabajo. También debe tenerse en cuenta la política de desconcentración de las grandes empresas multinacionales, sobre todo en momentos de crisis económica.

Esta situación obliga a considerar la importancia de la investigación en este sector y más si tenemos en cuenta que en la actualidad muchos bienes dependen del estado de la investigación científica o tecnológica, en la que la capacitación y la formación juegan un papel preponderante en las diferentes áreas de desarrollo de este sector.

Con el fin de dar una mirada al sector industrial colombiano, se han tomado textualmente algunos apartes de la investigación: "Demanda de recursos humanos en sectores productivos estratégicos", realizada por Fedesarrollo en 1998.

Crecimiento del Empleo: el crecimiento del empleo manufacturero se desaceleró en la década de los noventa, mientras que entre 1986 y 1990 el empleo creció a tasas anuales de 2.1\%. Entre 1991 y 1994 dicho crecimiento fue de sólo $0.6 \%$. El período de mayor generación de empleo en la industria tuvo lugar en la segunda mitad de los ochenta, luego de la crisis industrial de principios de la década. Sin embargo, 
las tasas de crecimiento del empleo han sido progresivamente menores desde 1987 hasta volverse negativas en 1994.

Esta disminución progresiva en el empleo del sector manufacturero se ha acentuado en los años recientes: entre 1995 y 1997 el empleo cayó 3.4\% por año. Incluyendo la trilla de café, la evolución del empleo manufacturero en este último período es comparable a la observada durante la crisis de principios de los ochenta.

Más de 50\% del empleo en la industria está concentrado en seis sectores: alimentos, textiles, confecciones, productos metálicos, otros químicos y bebidas. Los tres primeros sectores concentran más de una tercera parte del empleo manufacturero.

Nótese que la evolución del empleo está particularmente afectada por las caídas recientes (1995-1997). En efecto, hasta 1994 más de la mitad de los sectores industriales tenían un crecimiento promedio positivo del empleo, en algunos casos con tasas superiores al 3\% como derivados del petróleo, calzado, plásticos y equipo científico. En este mismo período, las mayores pérdidas en empleo se concentran en tabaco, hierro y acero, textiles, caucho y bebidas.

Es claro, por lo tanto, el gran deterioro del empleo manufacturero entre 1995 y 1997, que significó para el agregado una caída de $3.4 \%$ por año. Cerca del $30 \%$ de la disminución en el empleo en este período está concentrada en el sector alimentos y un 10\% adicional en el sector de plásticos.
Durante la apertura económica (19911994), los sectores con mayor dinamismo en el empleo han sido plásticos, otros químicos, objetos de barro, maquinaria no eléctrica y papel. Así mismo, los de mayores caídas en el empleo han sido químicos, cuero, refinerías y muebles ${ }^{18}$.

El texto anterior permite inferir algunas de las razones por las cuales, en los últimos años, el sector industrial colombiano ha reducido sus indicadores de competitividad. En las conclusiones encontramos que el estudio afirma:

Dentro de los sectores que aparecen como estratégicos en este contexto, están la industria de alimentos y bebidas, la fabricación de papel y sus productos, la industria química, la fabricación de productos plásticos, la fabricación de objetos de barro, loza y porcelana, las industrias básicas de metales no ferrosos, la fabricación de equipo de transporte y la fabricación de derivados del petróleo y carbón.

Dentro de la industria de alimentos se considera la fabricación de productos lácteos, el envasado de frutas y legumbres, la fabricación de cacao, chocolate y confitería y la destilación y rectificación de bebidas espirituosas. En la fabricación de papel se encuentra específicamente la fabricación de pulpa de madera, cartón y papel. En la industria química, la fabricación de resinas sintéticas, materias plásticas, la fabricación de pinturas, barnices y lacas, la fabricación de productos farmacéuticos y medicamentos y la fabricación de jabones, perfumes y cosméticos.

18 FEDESARROLLO. Demanda de recursos humanos en sectores productivos estratégicos. Informe investigativo. Santafé de Bogota, 1998. En: www.infoexport.copca.com/docs/copca/textcol.pdf 
Entre las industrias de metales no ferrosos se encuentran la fundición de estaño y níquel y la refinación de metales preciosos $^{19}$.

Por otra parte, el Ministerio de Desarrollo Económico en sus acuerdos sectoriales de competitividad, afirma:

El trabajo es el elemento central de interacción con los recursos físicos, el capital y la tecnología, y como tal, constituye un elemento esencial en el proceso de cambio. Elevar los niveles de productividad tendrá como resultado el aumento en los niveles de empleo, de salarios, y en general, de la calidad de vida de los colombianos. La formación y la capacitación de los recursos humanos son instrumentos fundamentales en los cuales hay que trabajar... ${ }^{20}$

Los párrafos anteriores permiten reafirmarnos en el planteamiento de trabajar alrededor de áreas como la mecatrónica, los procesos digitales artísticos y de diseño tridimensional, el diseño de productos, el desarrollo de materiales, el control y calidad, los procesos de producción, las modas y textiles y el diseño de interiores.

\section{SECTOR AGROPECUARIO}

Una mirada general al sector agropecuario en el ámbito internacional, nos obliga a ubicarnos un siglo atrás, época en que se da inició a una verdadera revolución en este sector con el objeto de satisfacer la demanda de alimentos generada por el crecimiento de la población mundial. Este proceso tuvo dos etapas de desarrollo. La primera se llevó a cabo durante la primera mitad del siglo veinte, con su principal estrategia de incremento de tierra cultivada y utilizando como herramienta la mecanización. La segunda etapa, llamada la "revolución verde" y cuyo desarrollo se llevó a cabo durante la segunda mitad del siglo veinte, se basó en el aumento de la productividad por unidad de área, teniendo como principal herramienta los insumos. ${ }^{21}$

Es importante destacar los impresionantes resultados. La producción de alimentos en los últimos 30 años se duplicó en África y triplicó en América Latina ${ }^{22}$, se amplió la oferta de alimentos de tal manera que los excedentes causaron una caída significativa de los precios $^{23}$.

No obstante, estos éxitos tuvieron costos muy significativos. Los recursos renovables (suelo, agua, aire, bosques y biodiversidad) han sido explotados más allá de su capacidad de recuperación. Los recursos no renovables (combustibles fósiles, minerales de alto valor, aguas subterráneas fósiles) han sido explotados sin pensar en las futuras generaciones. La contaminación ha sido mayor que la tasa de reciclamiento o absorción natural (Meadows, 1992).

Muchos países en desarrollo adoptaron la "revolución verde" como paradigma de desarrollo rural, con lo cual se registró un alza significativa en la producción agrícola.

19 Ibídem.

20 Ministerio de Desarrollo. Acuerdos de Competitividad. Bogotá, 1998.

21 PIEL, G. Only one world: Our own to make and a las mismas comunidades to keep. New York: United Nations Publication, 1992.

22 MEADOWS, D.H. Beyond the Limits. Vermont: Chelsea Green Publishing Co. Post Mills, 1992.

23 LUNDY M., C. F. OSTERTAG, R. B est. (2002). Value adding, Agro enterprise and poverty reduction: Globalization of agricultural research. Turialba: CATIE. En: www.redepapa.org/papandinal.pdf 
La agricultura es uno de los principales bastiones de apoyo para la economía de los países de América Latina. Sin embargo, estos logros han tenido su costo y han puesto en riesgo las principales fuentes de riqueza: la calidad de vida de la población, el agua y la diversidad.

Consecuentemente con lo anterior,

Lagran volatilidad que hoy caracteriza el mercado internacional de capitales,

hace que

en una

economíacon desequilibrios tan altos como la nuestra, existan riesgos considerables defuertes ajustes cambiarios. se hace necesaria una tercera etapa de la Revolución Agrícola, particularmente debido a que todos los indicadores -biofísicos, económicos y sociales- demuestran que una mejoría en la agricultura conduce a un desarrollo más balanceado ${ }^{24}$. Otros autores hablan de buscar fórmulas para trabajar en la promoción de un nuevo paradigma basado en la filosofía del desarrollo sostenible, cuya principal herramienta es la ecoeficiencia, la cual propende por la producción eficiente, la responsabilidad social, la viabilidad económica y la protección ambiental como complementos sinérgicos.

En Colombia, el sector agropecuario juega un papel prioritario dentro de las políticas de gobierno en aras a construir la paz, debido al abandono que ha sufrido el campo durante décadas por parte de la sociedad colombiana y del Estado. Esta es una de las causas que tienen hoy a Colombia dividida entre el país urbano y el país rural y entre el país moderno y el país atrasado.

La pobreza continúa afectando a más del 65\% de la población rural y las escasas oportunidades de progreso y de empleo lícito a que han llevado los procesos de reestructuración del sector agropecuario en la actualidad, representan obstáculos muy importantes para afianzar el sector.
A su vez, la población rural menos favorecida se localiza en gran medida en zonas ecológicamente frágiles y desarrolla sus actividades aplicando sistemas intensivos de producción, lo cual ocasiona un deterioro acelerado de recursos naturales estratégicos. Esto hace necesario un gran esfuerzo para mejorar el acceso de los productores del campo a recursos y tecnologías sostenibles que les permita progresar y frenar la pérdida de recursos naturales valiosos para el país.

Para modificar este escenario se necesita que el Estado genere condiciones a través de las cuales la sociedad vuelva sus ojos al campo para invertir en proyectos productivos, genere riqueza y empleo, explote las ventajas competitivas con tecnologías adecuadas, utilizando la mano de obra nacional y respetando el principio de sostenibilidad de los recursos productivos. La reactivación del sector agropecuario contribuye significativamente a lograr los propósitos de estabilización económica previstos. La gran volatilidad que hoy caracteriza el mercado internacional de capitales, hace que en una economía con desequilibrios tan altos como la nuestra, existan riesgos considerables de fuertes ajustes cambiarios.

En tal sentido, es conveniente para el país que se promueva una producción interna de alimentos básicos en condiciones competitivas y sin distorsiones comerciales, mediante la reactivación de la inversión agrícola y el fortalecimiento de las cadenas agroalimentarias promisorias. Esto demanda el diseño de instrumentos claros y transparentes y de apoyo a las iniciativas empresariales y campesinas que busquen 
generar riqueza y bienestar. Se trata de otorgar subsidios o exenciones a quienes inviertan en el campo y creen empleo.

Por lo anterior encontramos que en el ámbito productivo, los programas de gobierno y de entidades comprometidas con el sector buscan establecer nuevos proyectos y modelos en cadenas integradas de gran impacto regional, que fomenten la inversión y permitan la reconversión y modernización de la producción agropecuaria, elevando de manera significativa la competitividad, el volumen de la producción y las exportaciones con impactos positivos sobre la generación de empleo y riqueza en el contexto rural.

En concordancia con las ideas recién planteadas, las instituciones educativas del orden superior deben realizar ingentes esfuerzos por generar conocimientos prácticos aplicables al agro, en donde se produzca un flujo de información en dos sentidos: uno, que permita adquirir conocimientos de las comunidades, y luego, en una segunda instancia, revertirlos a las mismas comunidades debidamente conceptualizados y con tecnologías apropiadas.

El Observatorio de Competitividad del Ministerio de Agricultura y Desarrollo Rural de Colombia, a través del proyecto Agrocadenas Colombia, busca la competitividad sectorial en los planos nacional e internacional, razón por la cual se plantean las siguientes áreas de desarrollo: pesca industrial, acuicultura, apicultura, gestión ambiental y geología.

Tendencias de carácter internacional, alrededor del talento humano y del desarrollo empresarial, realzan la necesidad de formar personas en: recursos humanos, gestión empresarial y ciencias forenses.
La anterior caracterización sectorial finaliza esta primera parte. La propuesta de programas en cadena de formación (con qué) resultante del anterior análisis, así como la definición del mercado potencial de la educación a distancia en concordancia con esta propuesta programática (para quién), el cómo se plantea la oferta del servicio educativo y las regiones pertinentes dónde ofrecerse, serán los contenidos de la próxima entrega, tal como se enunció en la parte introductoria del presente documento.

\section{BIBLIOGRAFÍA}

- Ministerio de Trabajo y Seguridad Social (2004). Boletín comportamiento del mercado de trabajo. Bogotá.

- Ministerio de Educación Nacional (2004). Sistema Nacional de Información de la Educación Superior-SNIES. Bogotá.

- Ministerio de Trabajo y Seguridad Social y SENA (1998). Clasificación Nacional de Ocupaciones. Bogotá.

- Politécnico Grancolombiano (2004). PEI, documento de trabajo. Bogotá.

- Fedesarrollo (1998). Demanda de Recursos Humanos en Sectores Productivos Estratégicos, Informe investigativo. Santafé de Bogotá.

- Sena (1998). Indicadores del mercado laboral. Santafé de Bogotá: Grupo de publicaciones del Sena.

- Sena (1999). Estudio de caracterización de la logística en Colombia, Mesa sectorial de logística. Santafé de Bogotá: Editorial Precolombi.

- Sena (1999). Estudio de caracteriza-
Tendencias de carácter internacional, alrededor del talento humano $y$ del desarrollo empresarial, realzan la necesidad de formar personas en: recursos humanos, gestión empresarial y ciencias forenses. 
ción del mercadeo. Santafé de Bogotá: Editorial Precolombi.

- Sena (2000). Estudio de caracterización ocupacional del sector fibras, textil, confección en Colombia. Santafé de Bogotá: Editorial Grupo de publicaciones Sena, Dirección General.

- Sena (2001). Caracterización del Sector Salud. Bogotá: Editorial Grupo de publicaciones Sena, Dirección General.

- Sena (2000). Estudio de caracterización ocupacional del Sector de Servicios financieros. Santafé de Bogota: Editorial Grupo de publicaciones Sena, Dirección General.

- Sena (2002). Caracterización ocupacional de las telecomunicaciones en Colombia. Bogotá: Editorial Grupo de publicaciones Sena, Dirección General.

- Sena (1999). Caracterización Sectorial de Turismo en Colombia. Bogotá: Mimeo.

\section{PÁGINASWEB CONSULTADAS}

www.mineducacion.edu.co

www.tendenciasinternacionalesenlaedu-

cacioneningenierias

www.urosario.edu.co

wwwl.universia.net/CatalogaXXI/

default.asp?IDC=10032\&IDP=ES\&IDI

www.usfq.edu.ec www.fit.edu

www.uistmo.edu/

www.escuelaing.edu.co

www.audrey-cohen.edu/

www.ciis.edu/

www.ucm.es/

www.deusto.es

www.fu-berlin.de

www.asfh-berlin.de

www.fh-magdeburg.de

www.hfbk-dresden.de

www.ph-heidelberg

www.u-picardie.fr

www.univ-parisl.fr/

www.education.gouv.fr

www.colombiacompite.gov.co

www.agrocadenas.gov.co .

www.colombiacompite.gov.co

www.unad.gov.co

www.uned.es

www.ie.edu/ie/claustro_e_investigacion/claustro/catedrasM.htm

www.infoexport.copca.com/.docs/

copca/textcol.pdf

www.textil-confeccion.com.co/html/

articulos/alca1-1.htm

www.textil-confeccion.com.co/html/ articulos/articulos1_1.htm

www.upc.es/3er-cicle/cas/doctorat/programes/53.htm 